\title{
miR-17 92 cooperates with $R B$ pathway mutations to promote retinoblastoma
}

\author{
Karina Conkrite, ${ }^{1}$ Maggie Sundby, ${ }^{1}$ Shizuo Mukai, ${ }^{2}$ J. Michael Thomson, ${ }^{3}$ David $M u,{ }^{4,5}$ \\ Scott M. Hammond, ${ }^{3}$ and David MacPherson ${ }^{1,6}$ \\ ${ }^{1}$ Department of Embryology, Carnegie Institution, Baltimore, Maryland 21218, USA; ${ }^{2}$ Department of Ophthalmology, \\ Massachusetts Eye and Ear Infirmary, Harvard Medical School, Boston, Massachusetts 02114, USA; ${ }^{3}$ Lineberger Comprehensive \\ Cancer Center, School of Medicine, University of North Carolina School at Chapel Hill, Chapel Hill, North Carolina 27599, USA; \\ ${ }^{4}$ Department of Pathology, Pennsylvania State University College of Medicine, Hershey, Pennsylvania 17033, USA; ${ }^{5}$ Department of \\ Biochemistry and Molecular Biology, Pennsylvania State University College of Medicine, Hershey, Pennsylvania 17033, USA
}

The miR-17 92 cluster is a potent microRNA-encoding oncogene. Here, we show that miR-17 92 synergizes with loss of $\boldsymbol{R} \boldsymbol{b}$ family members to promote retinoblastoma. We observed miR-17 92 genomic amplifications in murine retinoblastoma and high expression of miR-17 92 in human retinoblastoma. While miR-17 92 was dispensable for mouse retinal development, miR-17 92 overexpression, together with deletion of $R b$ and $p 107$, led to rapid emergence of retinoblastoma with frequent metastasis to the brain. miR-17 92 oncogenic function in retinoblastoma was not mediated by a miR-19/PTEN axis toward apoptosis suppression, as found in lymphoma/

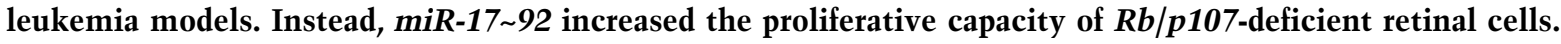
We found that deletion of $\boldsymbol{R} \boldsymbol{b}$ family members led to compensatory up-regulation of the cyclin-dependent kinase inhibitor p21Cip1. miR-17 92 overexpression counteracted p21Cip1 up-regulation, promoted proliferation, and drove retinoblastoma formation. These results demonstrate that the oncogenic determinants of $\mathrm{miR}-17 \sim 92$ are context-specific and provide new insights into $\mathrm{miR-17} 92$ function as an $R B$-collaborating gene in cancer.

[Keywords: retinoblastoma; $\mathrm{Rb}$; retina; microRNA; cancer; miR-17 92]

Supplemental material is available for this article.

Received May 16, 2011; revised version accepted July 8, 2011.

Study of retinoblastoma has led to critical insights into tumorigenesis. The $R B$ gene was the first tumor suppressor gene discovered. $R B$ is almost always mutated in human retinoblastoma and is also mutated in many other cancers such as small-cell lung, breast, bladder, brain, and others (Weinberg 1995; Corson and Gallie 2007; Burkhart and Sage 2008). Despite much research into the $R B$ family and cell cycle control, we still have a poor understanding of specific pathways that cooperate with $R B$ loss in tumorigenesis. Understanding such pathways may provide new therapeutic targets to treat $R B$-deleted tumors. Mouse models can help in the identification of genes that cooperate with $R B$ loss to promote retinoblastoma. In humans, deletion of $R B$ in the developing retina leads to frequent retinoblastoma. In contrast, mice with deletions in $R b$ alone are not retinoblastoma-prone (Clarke et al. 1992; Jacks et al. 1992; Lee et al. 1992). In the past, we generated some of the first $R b$ knockout mouse models of retinoblastoma by inactivating $R b$ together with one of its family members:

${ }^{6}$ Corresponding author.

E-mail macpherson@ciwemb.edu.

Article published online ahead of print. Article and publication date are online at http://www.genesdev.org/cgi/doi/10.1101/gad.17027411. p107 or $p 130$ (MacPherson et al. 2004, 2007). These models are ideal for identifying and understanding $R b$-cooperating pathways in cancer (Dyer and Bremner 2005; MacPherson and Dyer 2007; MacPherson 2008).

MicroRNAs represent novel candidates for $R B$-cooperating factors in retinoblastoma. Indeed, homozygous inactivation of Dicer led to suppression of murine retinoblastoma, suggesting that certain microRNAs may be critical for retinoblastoma (Lambertz et al. 2010). The microRNA cluster $m i R-17 \sim 92$ (Oncomir-1) was one of the first oncogenic microRNA clusters to be identified (He et al. 2005). miR-17 92 is found amplified or highly expressed across a wide spectrum of human cancers, including B-cell lymphomas and small-cell lung cancer (Ota et al. 2004; Hayashita et al. 2005; He et al. 2005). Oncogenic activity of $m i R-17 \sim 92$ has been best studied in lymphoma models, where overexpression cooperated with $M y c$ to accelerate lymphoma (He et al. 2005). More recently, one of the four families of microRNAs encoded by the polycistronic $m i R-17 \sim 92$ cluster, $m i R-19 a / b$, was found to confer $m i R-17 \sim 92$ oncogenic activity in murine lymphoma and leukemia models (Mu et al. 2009; Olive et al. 2009; Mavrakis et al. 2010). miR-19 acted to suppress apoptosis, largely via PTEN down-regulation. It will 
be critical to elucidate whether similar mechanisms underlie miR-17 92 oncogenic functions in other cancers, including solid tumors. For example, cell culture studies have provided evidence that cell cycle regulators may constitute important targets of miR-17 92 (Hayashita et al. 2005; Cloonan et al. 2008; Sengupta et al. 2009). Interestingly, miR-17 92 is an E2F target gene (Sylvestre et al. 2007; Woods et al. 2007) that would be predicted to be expressed in $R B$-deleted tumors, which have high E2F activity. However, miR-17 92 microRNA function in retinoblastoma has not yet been explored. Understanding mechanisms underlying miR-17 92 action across multiple tumor types is critical, as miR-17 92 microRNAs may constitute novel targets for therapies.

In this study, genomic analyses of mouse and human tumor samples implicate miR-17 92 for the first time as a potential oncogene and therapeutic target in retinoblastoma. Mouse genetic studies reveal important roles for miR-17 92 in collaborating with $R b$ family member loss in cancer of the retina by overcoming compensatory responses to $R b$ deletion. We found that human retinoblastoma cells were highly sensitive to inhibition of miR-17 92 microRNAs, providing a new therapeutic target for retinoblastoma. Our data firmly establish $m i R-17 \sim 92$ as an $R b$-cooperating gene in cancer and a critical regulator of proliferation in vivo.

\section{Results}

miR-17 92 is a target of amplification and is highly expressed in retinoblastoma

In human retinoblastoma, secondary alterations in addition to $R B$ mutation are important for tumorigenesis (Corson and Gallie 2007; MacPherson 2008). A murine retinoblastoma model initiated by mutations in the $R b$ family members $R b$ and $p 107$ ( $R b / p 107 D K O$ model) (Chen et al. 2004; MacPherson et al. 2007) exhibits tumorigenesis with long latency and partial penetrance, suggesting that additional alterations are critical for tumors to arise. We used ROMA, a form of array-CGH (Lakshmi et al. 2006), to study late stage tumors from this mouse model. We identified a region of the genome that underwent focal, high-level amplification. Of 21 tumors examined by ROMA, two exhibited focal 14qE amplifications, quantified by real-time PCR to be 5.5 -fold and ninefold (Fig. 1A; Supplemental Fig. 1A). The minimal common amplicon at $14 \mathrm{qE} 4$ was $650 \mathrm{~kb}$. This region harbored the miR-17 92 primary transcript and a fragment of the Gpc5 gene, with no other known genes present (Supplemental Fig. 1B). miR-17 92 encodes a cluster of six microRNAs produced from a single transcript that can be grouped into four families based on seed sequence (Fig. 1B). Small RNA Northern blots confirmed increased expression of miR-17 92 component microRNAs upon 14qE4 amplification (Fig. 1C).

There are two paralogs for this microRNA cluster: $m i R-106 b \sim 25$ and miR-106a 363 (Fig. 1B). Functional overlap between miR-17 92 and miR-106b 25 has already been shown to be important for mouse development
(Ventura et al. 2008). Like miR-17 92, miR-106b 25 has also been implicated in human cancers (Ivanovska et al. 2008; Poliseno et al. 2010). We found that miR-106b 25 underwent copy number increase in one of 21 murine retinoblastomas via a 14-Mb 5qG2-3 gain (Supplemental Fig. 2A).

To assess whether miR-17 92 was also a target for amplification in human retinoblastoma, we performed array-CGH on DNA from human samples using customdesigned high-density Nimblegen arrays that tiled across the miR-17 92 locus. Among a panel of 32 human retinoblastomas, one tumor exhibited a focal, but low-level, miR-17 92 gain (Fig. 1D). A second human retinoblastoma exhibited a large $13 \mathrm{q}$ gain that also resulted in miR-17 92 copy number increase. We also examined miR-106b 25, which is located within an intron of the MCM7 gene on chromosome 7q22.1. Low-level copy number increase was evident in four of 32 human retinoblastomas (Supplemental Fig. 2B). Thus, miR-17 92 and its paralog, miR-106b 25, undergo copy number increase in a subset of murine and human retinobolastomas, but high-level alterations were observed only in murine retinoblastoma. Since only a small subset of human retinoblastomas underwent copy number alterations at the miR-17 92 locus, and these were low-level, we then investigated whether other mechanisms could lead to high miR-17 92 expression.

\section{Microarray and deep-sequencing analyses} of microRNAs in retina and retinoblastoma

We examined global expression of microRNAs in human and murine retinoblastoma using microarrays. Three primary human retinoblastomas and two human retinoblastoma cell lines, as well as eight primary murine retinoblastomas from two different mouse models (four $\mathrm{Rb} / \mathrm{p} 107 \mathrm{DKO}$ and four $R b / p 130 D K O$ tumors) (see MacPherson et al. 2007) were included in the analysis, along with normal murine retinas (embryonic day 18.5 [E18.5] and adult). High similarity between human and mouse microRNA sequence allowed for comparison of expression levels between human and mouse retinoblastoma. In human retinoblastoma, primary tumors, and cell lines, some of the most highly expressed microRNAs were members of the miR-17 92 cluster and its paralogs (Fig. 1F). MicroRNA array analyses and small RNA Northern blots showed that miR-17 92 and related microRNAs were expressed at a lower but significant level in murine retinoblastoma, except for cases where genomic amplification of miR-17 92 was evident (Fig. 1E,F). Small RNA deep sequencing of two primary human retinoblastomas revealed that members of the $m i R-20$ family (i.e., $m i R-20$ / miR-17/miR-106b/miR-93) were among the most highly expressed microRNAs (Table 1; Supplemental Table 1). This family represented $>6 \%$ of all of the sequenced reads that corresponded to known microRNAs. Deep sequencing also revealed that the high miR-20 family expression derived from both $m i R-17 \sim 92$ and $m i R-106 b \sim 25$ paralogs. In contrast to the high miR-20 family expression, miR-19 family members were expressed at a much lower 

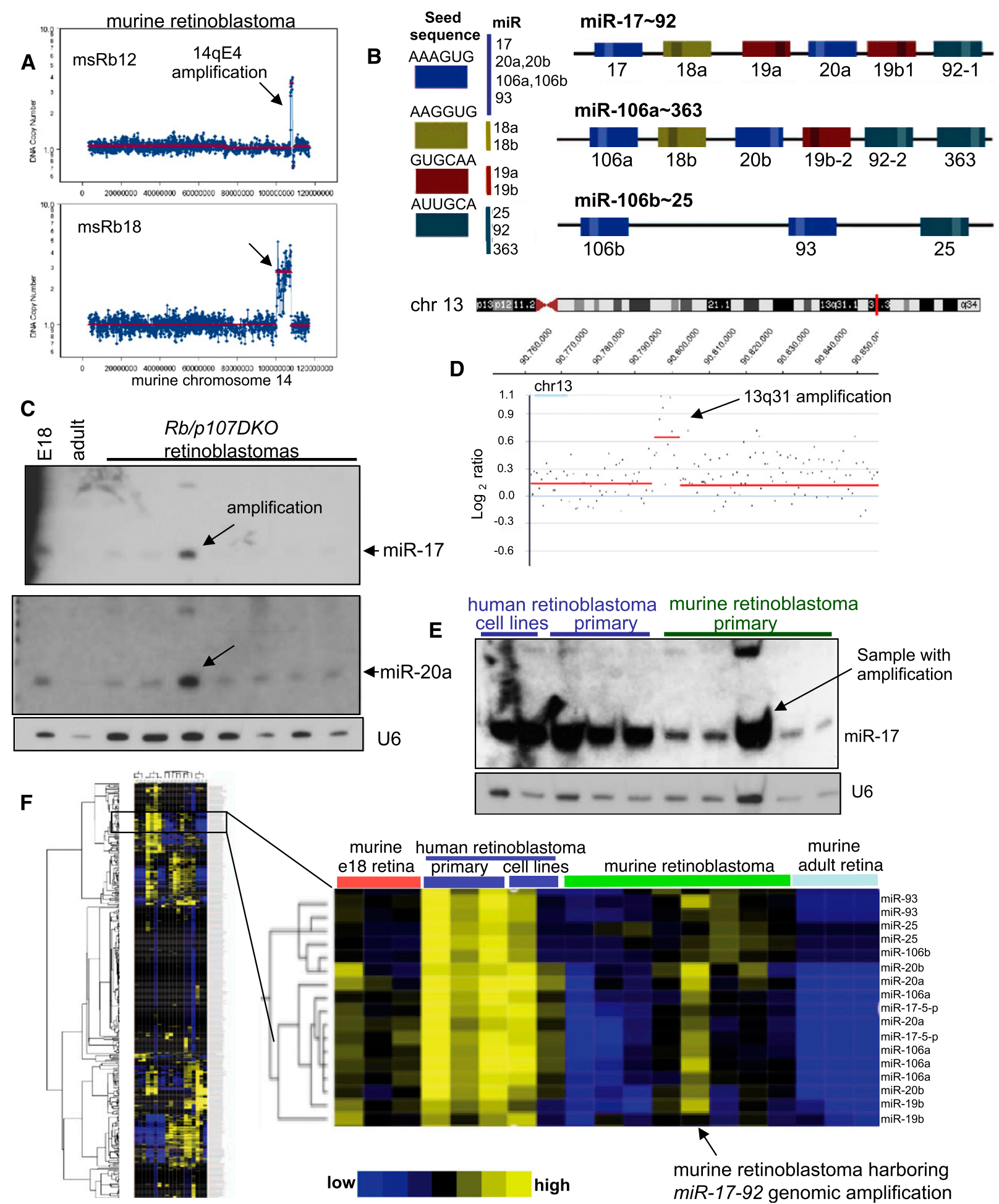

human retinoblastoma murine retinoblastoma
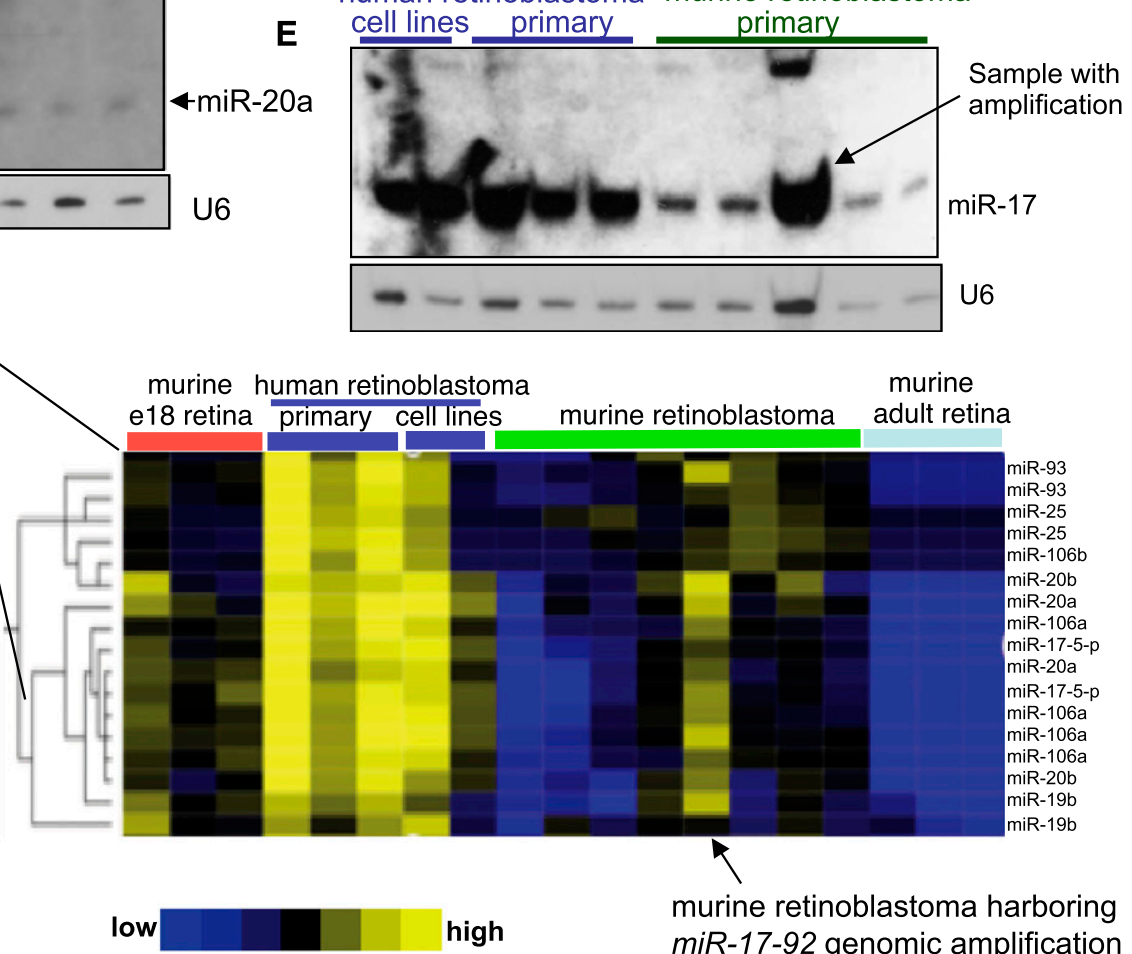

murine retinoblastoma harboring miR-17-92 genomic amplification

Figure 1. $m i R-17 \sim 92$ is amplified/highly expressed in retinoblastoma. (A) ROMA plot showing chromosome 14 data from two murine $\mathrm{Rb} / \mathrm{p} 107 \mathrm{DKO}$ retinoblastomas harboring high-level 14qE amplifications that include the miR-17 92 locus. (B) Schematic of microRNAs from the $m i R-17 \sim 92$ locus and its two paralogs, miR106a 363 and miR106b 25. MicroRNA families with identical seed sequences are indicated. $(C)$ Small RNA Northern blot showing levels of miR-17 and miR-20a in murine retinoblastomas compared with normal retina. A tumor with a high-level miR-17 92 amplification is indicated (arrow). (D) Array-CGH analysis showing a focal region of 13q31 with a 6.65-kb amplification at the human miR-17 92 locus. (E) Small RNA Northern blot showing level of expression of miR-17 in murine retinoblastomas compared with human retinoblastomas and with Y79 and Weri-Rb1 retinoblastoma cell lines. $(F)$ Microarray analyses showing genome-wide microRNA expression in human primary retinoblastoma and cell lines, murine retinoblastoma, and normal murine retina. The magnified region shows expression of microRNAs from miR-17 92 and paralogs. 
Table 1. Most highly expressed microRNAs in human retinoblastoma and FW18 fetal retina

\begin{tabular}{|c|c|c|c|}
\hline \multicolumn{2}{|c|}{ FW18 human retina } & \multicolumn{2}{|c|}{ Primary human retinoblastoma } \\
\hline MicroRNA & $\begin{array}{c}\text { Normalized } \\
\text { reads }\end{array}$ & MicroRNA & $\begin{array}{c}\text { Normalized } \\
\text { reads }\end{array}$ \\
\hline hsa-miR-9 & $17.8 \%$ & hsa-miR-182 & $21.0 \%$ \\
\hline hsa-miR-182 & $7.0 \%$ & hsa-miR-183 & $13.0 \%$ \\
\hline hsa-miR-181a & $7.3 \%$ & hsa-miR-96 & $4.8 \%$ \\
\hline hsa-let-7f & $4.9 \%$ & hsa-miR-124 & $3.1 \%$ \\
\hline hsa-let-7a & $4.1 \%$ & hsa-miR-30d & $3.0 \%$ \\
\hline hsa-miR-183 & $2.7 \%$ & hsa-miR-21 & $2.9 \%$ \\
\hline hsa-miR-30d & $3.4 \%$ & hsa-miR-103 & $2.8 \%$ \\
\hline hsa-miR-217 & $3.1 \%$ & hsa-miR-1246 & $2.6 \%$ \\
\hline hsa-miR-30a & $2.7 \%$ & hsa-let7a & $2.3 \%$ \\
\hline hsa-let-7g & $1.9 \%$ & hsa-miR-9 & $2.0 \%$ \\
\hline hsa-miR-20a ${ }^{a}$ & $2.2 \%$ & hsa-miR-93 ${ }^{a}$ & $2.0 \%$ \\
\hline hsa-miR-30e & $2.4 \%$ & hsa-miR-7 & $1.9 \%$ \\
\hline hsa-miR-96 & $1.4 \%$ & hsa-miR-20a $a^{a}$ & $1.9 \%$ \\
\hline hsa-miR-101 & $2.1 \%$ & hsa-miR-217 & $1.8 \%$ \\
\hline hsa-miR-103 & $1.7 \%$ & hsa-miR-30e & $1.8 \%$ \\
\hline hsa-miR-92a & $1.8 \%$ & hsa-let-7f & $1.7 \%$ \\
\hline hsa-miR-21 & $1.5 \%$ & hsa-miR-101 & $1.6 \%$ \\
\hline hsa-miR-30c & $1.4 \%$ & hsa-miR-106 $b^{a}$ & $1.6 \%$ \\
\hline hsa-miR-181b & $1.2 \%$ & hsa-miR-143 & $1.6 \%$ \\
\hline hsa-miR-26a & $1.2 \%$ & hsa-miR-148b & $1.2 \%$ \\
\hline hsa-miR-93 ${ }^{a}$ & $1.5 \%$ & hsa-miR-181a & $1.2 \%$ \\
\hline hsa-miR-216a & $1.6 \%$ & hsa-miR-92a & $1.1 \%$ \\
\hline hsa-miR-106 $b^{a}$ & $1.3 \%$ & hsa-miR-378 & $1.1 \%$ \\
\hline hsa-miR-99b & $1.0 \%$ & hsa-miR-26a & $1.1 \%$ \\
\hline hsa-miR-130a & $1.1 \%$ & hsa-miR-216a & $1.0 \%$ \\
\hline hsa-miR-216b & $1.1 \%$ & hsa-miR-25 & $0.9 \%$ \\
\hline hsa-miR-335 & $0.9 \%$ & hsa-miR-30b & $0.9 \%$ \\
\hline hsa-miR-124 & $0.7 \%$ & hsa-miR-17 ${ }^{a}$ & $0.9 \%$ \\
\hline hsa-miR-17 ${ }^{\mathrm{a}}$ & $0.8 \%$ & hsa-miR-99b & $0.8 \%$ \\
\hline hsa-miR-148a & $0.7 \%$ & hsa-miR-16 & $0.8 \%$ \\
\hline
\end{tabular}

Data are from Illumina deep sequencing. Percent normalized reads are averaged from two primary retinoblastomas and two FW18 human retinas. Unaveraged values of all detected microRNAs for the individual samples are shown in Supplemental Table 1. Members of miR-17 92 cluster and paralogs are in bold. ${ }^{a}$ MicroRNAs from the miR-17/20/106/93 family.

level in retinoblastoma. We also sequenced microRNAs from two human retinas at fetal week 18 (FW18), as retinoblastoma is highly likely to initiate in the developing retina. The $m i R-20$ family was again one of the most highly expressed microRNA families in normal fetal human retina (Table 1; Supplemental Table 1). These data indicate that genomic amplification at the $m i R$ 17 92 locus is not necessary for high expression of $\mathrm{miR}$ 17 92 and related microRNAs in human retinoblastoma. Our data suggested that high $m i R-17 \sim 92$ levels might confer a selective advantage upon cells that have the potential to form retinoblastoma.

miR-17 92 and miR-106b 25 are dispensable for mouse retinal development

We used TaqMan microRNA analysis to determine the pattern of expression of a panel of $m i R-17 \sim 92$ component microRNAs during retinal development in wild-type mice. $m i R-17 \sim 92$ members $\operatorname{miR}-17$, miR19a, miR-92, and miR-20a were expressed at proliferative stages of murine retinal development (E13.5 and postnatal day 0 [P0]); expression decreased at late stages in retinal development (P10) and was nearly extinguished in adult retina (Fig. 2A). To assess normal roles for $m i R-17 \sim 92$ in the developing retina, we inactivated $m i R-17 \sim 92$ using tissue-specific knockout approaches. We used Nestin Cre transgenic mice to drive deletion of a floxed allele in which $m i R$ 17 92 is flanked by $\operatorname{lox} P$ sites (Ventura et al. 2008). The Nestin Cre system has been used as a system to probe roles for genes in retinal development and leads to complete deletion in early progenitors in the retina and throughout the nervous system (MacPherson et al. 2004; Martins et al. 2008). We also coinactivated the miR-17 92 paralog $m i R-106 b \sim 25$, as deep-sequencing data indicated that both paralogs were highly expressed in human retinoblastoma. Also, functional overlap between these clusters has been previously demonstrated in vivo /Ventura et al. 2008). We measured proliferation and examined retinal histology in newborn animals (P0) (Fig. 2B,C). No differences in the histological appearance of the retina or levels of BrdU incorporation were found. To examine cell fate specification, we tested a panel of markers that labeled major retinal cell types at P22, a stage when retinal histogenesis is complete (Fig. 2D). These markers included calbindin (horizontal cells), syntaxin (amacrine cells), calretinin (amacrine subset), M-Opsin (cone subset), and glutamine synthetase/sox2 (colabeling Müller glia). Each of these cell types were specified normally, even in the absence of $m i R-17 \sim 92$ and $m i R-106 b \sim 25$. We also confirmed these findings using the Pax6 $\alpha$ Cretransgenic strain that drives deletion specifically in the retina (data not shown). These experiments showed that miR-17 92 and miR-106b 25 were dispensable for murine retinogenesis.

\section{miR-17 92 overexpression accelerates retinoblastoma}

Based on our observations of $m i R-17 \sim 92$ overexpression in human retinoblastoma and in a subset of murine retinoblastomas, we sought to determine whether overexpression of $m i R-17 \sim 92$ would promote retinoblastoma. To this end, we made use of mice that harbored an allele of $\operatorname{miR}-17 \sim 92$ (referred to as $R 26^{17 \sim 92}$ ) wherein a loxstop-lox cassette upstream of $m i R-17 \sim 92$ allows for a low level of ectopic expression upon a Cre-mediated recombination event (Xiao et al. 2008). Similar to our observations from loss-of-function studies, retinas from Pax6 $\alpha$ Cre R26 $6^{17 \sim 92} / R 26^{17 \sim 92}$ mice with retina-specific miR-17 92 overexpression resembled those from wildtype mice (Supplemental Fig. 3). It is possible that the lack of detectable phenotypes in such animals may reflect the low extent of $m i R-17 \sim 92$ overexpression using this allele (Xiao et al. 2008; data not shown). Aging such mice up to a year of age revealed that $m i R-17 \sim 92$ overexpression does not initiate retinoblastoma in the absence of additional mutations (data not shown). $R 26^{17-92}$ mice were then bred to the $R b^{\text {lox/lox }} ; p 107^{-1-} ; \alpha$ Cre (i.e., $\mathrm{Rb} / \mathrm{p} 107 \mathrm{DKO}$ ) mouse retinoblastoma model to generate 


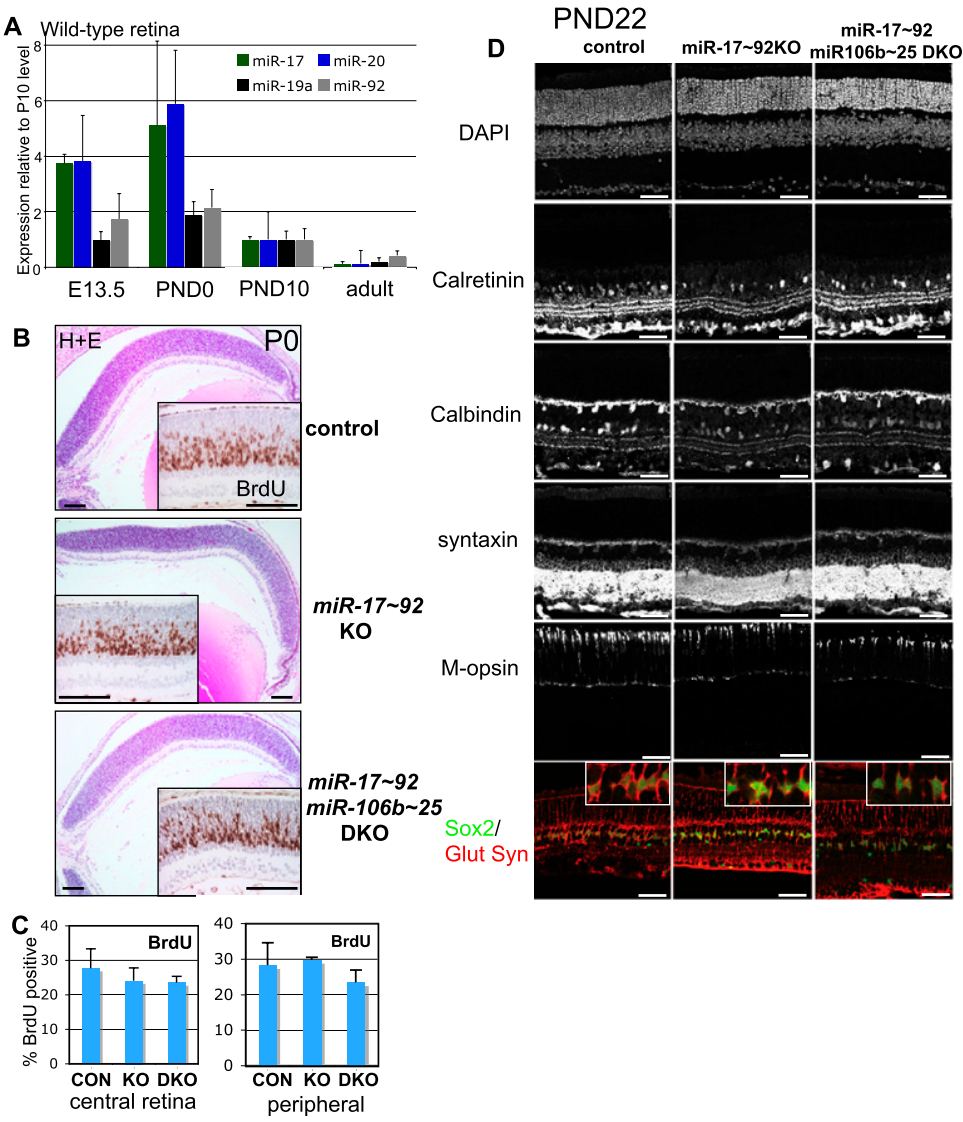

Figure 2. $m i R-17 \sim 92$ and $m i R-106 b$ are dispensable for mouse retinal development. (A) TaqMan microRNA assay showing expression of a subset of miR-17 92 microRNAs in the murine retina at differing times during development. $n=4$ independent samples per time point. (B) Hematoxylin and eosin $(\mathrm{H}+\mathrm{E})$ staining of retinas from control, NesCre miR-17 92 $10 x / 10 x$ ( $\mathrm{miR}-17 \sim 92 \mathrm{KO}$ ), and $\mathrm{miR}-17 \sim 92^{\text {lox } / l o x} ; \mathrm{miR}-106 \mathrm{~b} \sim 25^{-/-}$ $(D K O)$ newborn $(\mathrm{PO})$ animals. (Inset) BrdU proliferation analyses. Bar, $100 \mu \mathrm{m} .(C)$ Quantification of percent of BrdU-positive cells in peripheral and central retina ( $n=4$ independent retinas per genotype). (D) Confocal images showing normal expression of markers of retinal cell types in $m i R-17 \sim 92 K O$ and $m i R-17 \sim 92$; miR106b 25DKO retinas versus controls that lack NesCre expression. Bar, $50 \mu \mathrm{m}$. Error bars in the figure indicate the standard deviation.
$R b / p 107 D K O$ mice with or without the $R 26^{17-92}$ allele (Fig. 3A). At P22, miR-17 92 remains expressed in the $R b / p 107 D K O ; R 26^{17-92} / R 26^{17-92}$ retina, but such expression is nearly extinguished in controls (Fig. 3B). We aged cohorts of 30 mice per genotype and followed them for the presence of retinoblastoma that invaded the anterior chamber of the eye (Fig. 3C, inset). Upon initial appearance of retinoblastoma in one eye, we continued to monitor the animals for the appearance of bilateral retinoblastoma in the anterior chamber of the second eye. While $R b / p 107 D K O$ retinoblastomas arose with delayed kinetics and low penetrance as previously shown (MacPherson et al. 2007), miR-17 92 overexpression coupled with $R b / p 107$ loss led to rapid retinoblastoma emergence (Fig. 3C). We found that the effect of $m i R-17 \sim 92$ was dosage-dependent; animals harboring two copies of $R 26^{17 \sim 92}$ allele exhibited shorter latency to development of externally visible retinoblastoma. Remarkably, by just $70 \mathrm{~d}$, over half of the $R 26^{17-92} / R 26^{17-92} ; R b / p 107 D K O s$ exhibited bilateral retinoblastoma with anterior chamber invasion (Fig. 3D). At this stage, we did not observe retinoblastoma in $R b / p 107 D K O$ animals (Supplemental Fig. 4). Retinoblastoma in the $R 26^{17-92} / R 26^{17-92} ; R b / p 107 D K O$ model was highly invasive, with tumor cells observed in the optic nerve (Fig. 3F). Histological analyses of brains on a subset of animals with late stage retinoblastoma revealed brain metastasis in four of nine $R 26^{17-92} / R 26^{17-92}$; $R b / p 107 D K O$ animals examined (Fig. 3G). Given the strong effects of $m i R-17 \sim 92$ overexpression on retinoblastoma emergence in the $R b / p 107 D K O$ model, we wondered whether the absence of $p 107$ would still be required for retinoblastoma in the context of $m i R-17 \sim 92$ overexpression. Histological examination of $R b^{\text {lox/lox }}$; $R 26^{17-92 /+}$ animals at up to 1 yr of age did not reveal the presence of retinoblastoma (data not shown), indicating that inactivation of an additional $R b$ family member is still required for retinoblastoma in mice even upon $\mathrm{miR}-17 \sim 92$ overexpression.

We performed immunostaining to characterize retinoblastomas that arose in the $R b / p 107 D K O ; m i R-17 \sim 92-$ overexpressed model. $R b / p 107 D K O ; R 26^{17-92} / R 26^{17-92}$ tumors widely expressed syntaxin, which labels amacrine cells and horizontal cell processes (Fig. 3D). Syntaxin staining is consistent with amacrine features described in previously described retinoblastoma models (RobanusMaandag et al. 1998; Chen et al. 2004; MacPherson et al. 2004; Zhang et al. 2004). In addition, we found Sox2 to be expressed in the vast majority of tumor cells in three of three tumors (Fig. 3D). Sox2 labels progenitor cells during retinal development and Müller glia in the adult retina. Tumor analysis by transmission electron microscopy (TEM) revealed the presence of synaptic densities in retinoblastoma rosettes (Fig. $3 \mathrm{E}$ ). This indicated that $R b / p 107 D K O ; R 26^{17 \sim 92} / R 26^{17 \sim 92}$ retinoblastoma cells exhibit some characteristics of differentiated neurons also found in other retinoblastoma models (Johnson et al. 
A

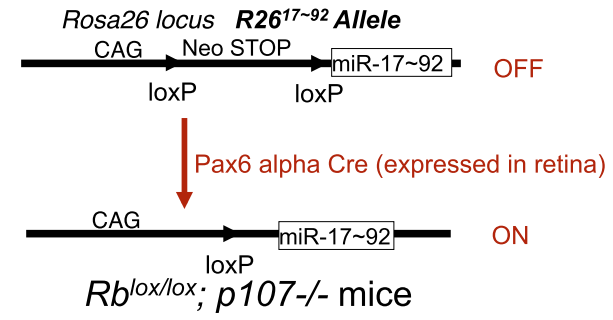

C
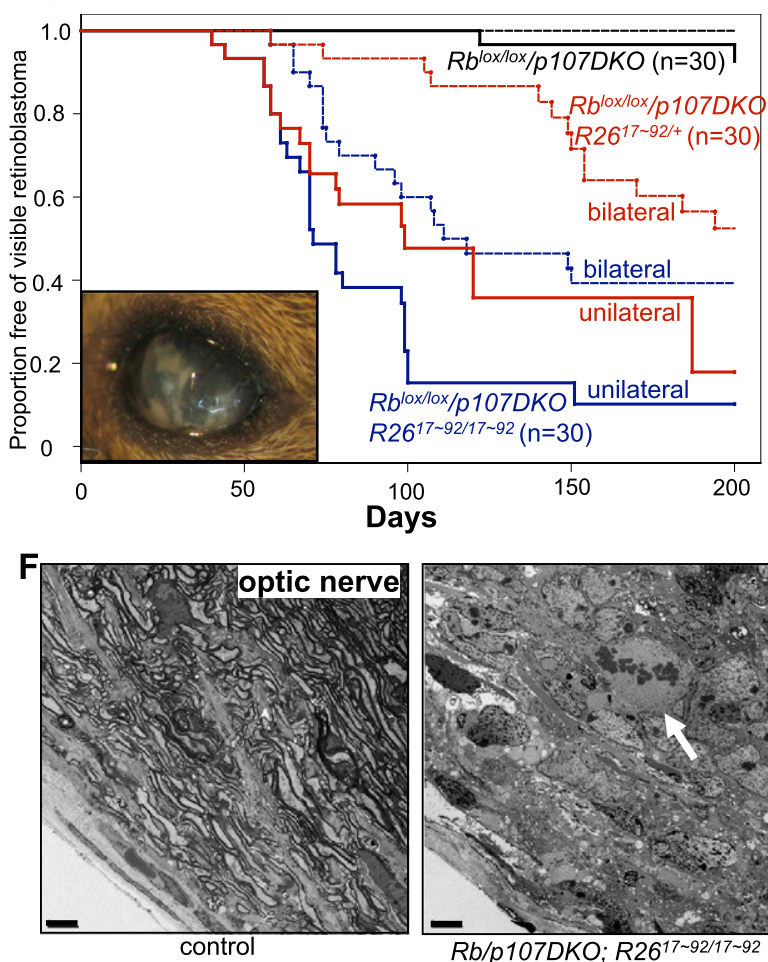

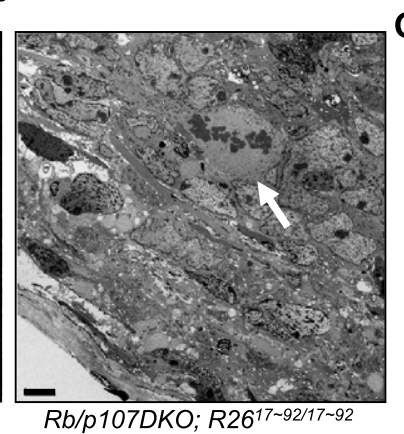

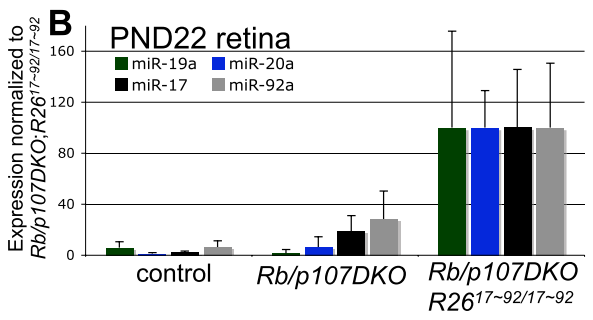

D
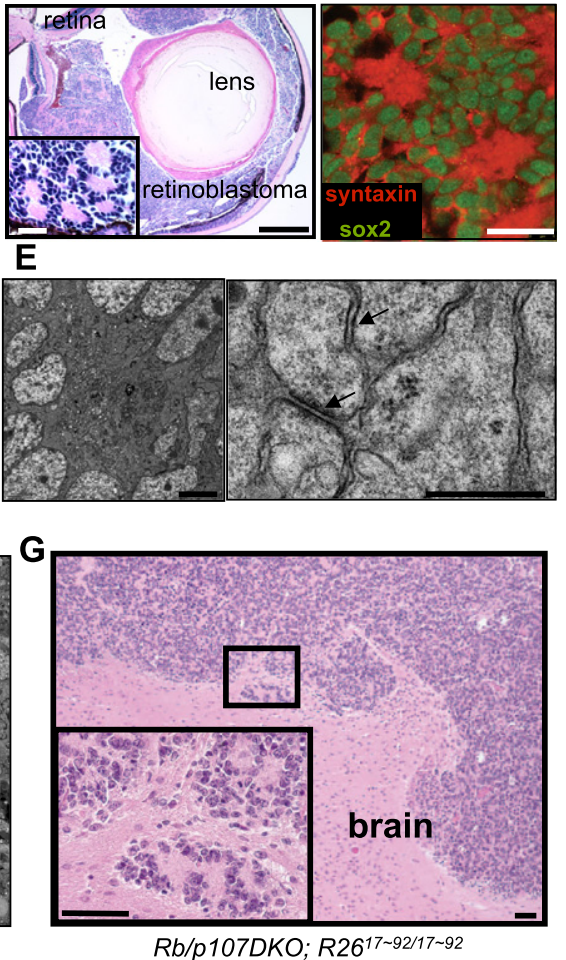

Figure 3. Overexpression of $m i R-17 \sim 92$ synergizes with $R b$ family member deletion to promote retinoblastoma. (A) Schematic of strategy used to delete $R b$ and activate miR-17 92 expression in p107-deficient mice using Pax6 $\alpha$-enhancer Cre. (B) TaqMan microRNA assay showing increased expression of $m i R-17 \sim 92$ component microRNAs in peripheral P22 retina from $R b / p 107 D K O$ $R 26^{17 \sim 92} / R 26^{17 \sim 92}$ mice. Error bars indicate the standard deviation. $(C)$ Observational curves showing time to first appearance of invasive retinoblastoma in the anterior chamber of the eye (see the inset). Mice continued to be followed for appearance of retinoblastoma in the anterior chamber of the second eye. (D) Histology of an $R b / p 107 D K O R 26^{17 \sim 92} / R 26^{17 \sim 92}$ eye at 2 mo of age. (Inset) The tumor has invaded the anterior chamber and exhibits the presence of rosettes. Immunostaining reveals widespread staining for both syntaxin and Sox 2 in three of three tumors analyzed. Bars: black bar, $500 \mu \mathrm{m}$; white bar, $25 \mu \mathrm{m}$. (E) TEM reveals differentiated features to tumor cells, including the presence of synaptic densities (arrows) in the central plexus of a retinoblastoma rosette. Bar, $5 \mu \mathrm{m}$. (F) TEM analysis of optic nerve showing invasion by retinoblastoma tumor cells. A mitotic tumor cell is indicated (arrow) Bar, $5 \mu \mathrm{m}$. (G) $\mathrm{H}+\mathrm{E}$ showing brain metastasis. Bar, $50 \mu \mathrm{m}$.

2007). Our findings of high expression of Sox2, however, raises the possibility that despite differentiated features, the tumors may originate from a more primitive cell. The potent activity of miR-17 92 in driving retinoblastoma progression prompted us to investigate the mechanism through which miR-17 92 acted.

miR-17 92 overexpression synergizes with $R b$ family inactivation to increase retinal proliferation

We examined the properties of early lesions in $R b /$ $p 107 D K O$ versus $R b / p 107 D K O ; R 26^{17 \sim 92} / R 26^{17 \sim 92}$ mice at P12 (Fig. 4A; Supplemental Fig. 5). At this stage, three distinct layers are found in control retinas, but the $\mathrm{Rb} / \mathrm{p} 107 D K O$ mutant peripheral retina is disorganized. Similar disorganization is observed in $R b / p 107 D K O$; $R 26^{17 \sim 92} / R 26^{17 \sim 92}$ retina, which is expanded compared with $R b / p 107 D K O$ retina. All cells have exited the cell cycle by P12 in controls, as shown by phospho-histone H3 (PH3) labeling of mitotic cells (Fig. 4B). However, we found inappropriate proliferation in $R b / p 107 D K O s$, and the level of proliferation is increased when miR-17 92 overexpression is coupled with $R b / p 107$ deletion (Fig. $4 \mathrm{~B}, \mathrm{D})$. By P22, proliferation is sharply decreased in $R B / p 107 D K O s\left(0.6 \%\right.$ of cells were $\left.\mathrm{PH}^{+}\right)$, while there were no proliferating cells in controls (Fig. 4D; Supplemental 


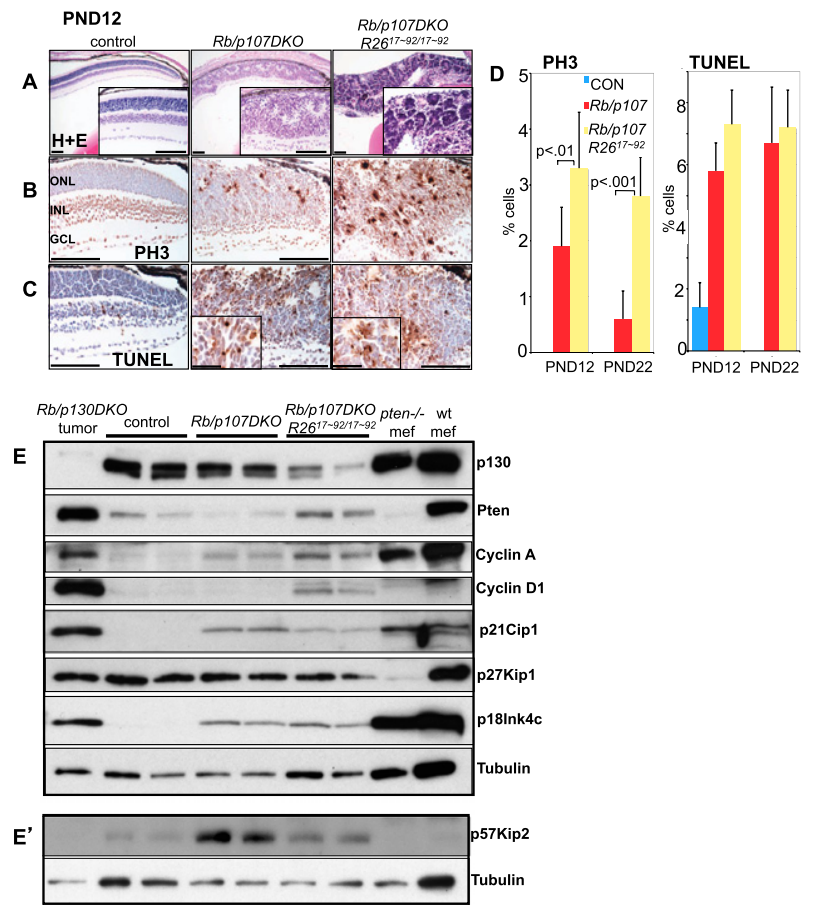

Figure 4. $m i R-17 \sim 92$ overexpression increases proliferation without suppressing apoptosis in $R b / p 107 D K O$ retina. $(A) \mathrm{H}+\mathrm{E}$ showing histology of peripheral retina in controls (lacking Cre expression), $R b / p 107 D K O$, and Rb/p107DKO R26 ${ }^{17 \sim 92} / R 26^{17 \sim 92}$ retinas at P12. Bar, $100 \mu \mathrm{m}$. (B) PH3 immunostaining with labeling of mitotic cells at P12. Bar, $100 \mu \mathrm{m} .(C)$ TUNEL analysis showing levels of apoptosis at P12. Bars: $100 \mu \mathrm{m}$; inset, $50 \mu \mathrm{m}$. $(D)$ Quantification of TUNEL and PH3 data. Error bars in figure indicate the standard deviation. $P$-value from Student's $t$-test is indicated. $\left(E, E^{\prime}\right)$ Western blot analyses showing protein levels of cell cycle regulators and PTEN in P12 peripheral retina extracts or control extracts. Note the decreased expression of p130, p21Cip1, and p57Kip2 in Rb/p107DKO R26 17 92 /R26 $6^{17 \sim 92}$ compared with $R b / p 107 D K O$ samples.

Fig. 7). With $m i R-17 \sim 92$ overexpression, however, the level of proliferation was strongly increased and lesions with histological similarities to retinoblastoma were observed. In previously described lymphoma models, miR-17 92 suppressed apoptosis by down-regulating PTEN (Mu et al. 2009; Olive et al. 2009). In contrast, PTEN protein levels were not suppressed in P12 retina extracts that had $R b / p 107$ loss coupled with $m i R-17 \sim 92$ overexpression (Fig. 4E). Also, we found no suppression of apoptosis in emerging lesions at P12 and P22 upon miR-17 92 overexpression (Fig. 4 C,D; Supplemental Figs. $5 \mathrm{~B}, 7)$. In the $R 26^{17 \sim 92} / R 26^{17 \sim 92} ; R b / p 107 D K O \mathrm{P} 12$ retina, we observed pools of necrotic cells that were not observed in the $R b / p 107 D K O$ retinas (Supplemental Fig. 5A). These necrotic regions were excluded from the quantification of TUNEL-positive cells in Figure 4D. Overall, these data are indicative of increased cell death in $R b / p 107 D K O R 26^{17 \sim 92} / R 26^{17 \sim 92} \mathrm{P} 12$ retinas. Consistent with these results, levels of cleaved caspase 3 and cleaved PARP were strongly elevated in such mutants compared with the levels in $R b / p 107 D K O$ retina (Sup- plemental Fig. 5B). Together, these data suggested that miR-17 92 promoted retinoblastoma by increasing the levels of proliferation without suppressing apoptosis.

miR-17 92 overexpression counteracts compensatory cyclin-dependent kinase inhibitor (CDKI) up-regulation that follows $\mathrm{Rb}$ family mutation

We hypothesized that $\mathrm{miR}-17 \sim 92$ overexpression might promote proliferation by counteracting compensatory responses to $R b / p 107$ deletion. Factors that would allow the remaining $R b$ family member, p130, to enforce cell cycle exit/arrest were particularly interesting candidates, as p130 is a potent suppressor of retinoblastoma in mice (MacPherson et al. 2007). At the level of RNA, we did not find compensatory up-regulation of p130 expression in $R b / p 107 D K O$ versus control $p 107^{-/-}$retinas at $\mathrm{P} 12$ (Supplemental Fig. 6). We did, however, observe widespread compensatory up-regulation of CDKIs. Transcripts for p21Cip1, p18Ink4c, p16Ink4a, p15Ink4b, and p57Kip2 were all robustly increased in response to $\mathrm{Rb} / \mathrm{p} 107$ loss (Supplemental Fig. 6). We hypothesized that one or more of the up-regulated negative cell cycle regulators might be suppressed by $m i R-17 \sim 92$. However, real-time PCR analysis showed that $m i R-17 \sim 92$ overexpression did not suppress CDKI up-regulation at the RNA level (Supplemental Fig. 6). Since microRNAs can suppress translation in the absence of transcriptional alterations, we then performed Western blot analysis on P12 peripheral retina extracts. We found protein levels of the CDKIs p21Cip1 and p57Kip2 to be strongly suppressed upon $m i R-17 \sim 92$ expression compared with $R b / p 107 D K O$ retina alone (Fig. 4E, E'). p21Cip1 is a well-characterized target for miR-17 92 family members, with a 3 ' untranslated region (UTR) that is directly regulated by microRNAs in the $\mathrm{miR}-17 / \mathrm{miR}-20 / \mathrm{mir}-106$ family (Ivanovska et al. 2008). p57Kip2 is also a validated $m i R-17 \sim 92$ target with a 3' UTR harboring binding sites for miR-92 (Sengupta et al. 2009). miR-17 92 status was not associated with alteration in the protein levels of another CDKI that is also up-regulated upon $R b / p 107$ loss, p18INK4c, but lacks 3' UTR-binding sites for miR-17 92 family members (Fig. 4E). Interestingly, p130 protein levels were also reduced when $\mathrm{miR}-17 \sim 92$ was overexpressed together with $R b / p 107$ deletion (Fig. 4E). p130 has also been reported to be a direct target for $m i R-17 \sim 92$-encoded microRNAs (Lu et al. 2007; Wang et al. 2008). Decreased p130 expression may be highly significant, as p130 synergizes potently with $R b$ loss to promote retinoblastoma in mouse models (MacPherson et al. 2007). p130 expression is highly cell cycle-dependent, and decreased levels could also be secondary to increased proliferation driven by other $m i R-17 \sim 92$ effectors. Our molecular analyses showed increased expression of cyclin D1 and A, indicative of broad alterations in the proliferation machinery associated with $m i R-17 \sim 92$ expression coupled with $R b / p 107$ loss (Fig. 4E). Overall, these data support the findings that $m i R-17 \sim 92$ promotes increased proliferation without suppressing cell death in the $R b / p 107-d e-$ ficient retina. Moreover, these analyses provided candidate 
effectors of miR-17 92 that might promote proliferation in the context of $R b$ family member deletion.

\section{miR-17/20 inhibition suppresses proliferation in cultured human retinoblastoma cells}

To provide mechanistic insights into $m i R-17 \sim 92$ function in retinoblastoma cells, we turned to studies of cell lines that harbored high $m i R-17 \sim 92$ expression; i.e., human retinoblastoma cell lines Y79 and Weri-Rb1 (Fig. $1 \mathrm{E}, \mathrm{F})$. We tested whether inhibition of specific $m i R-17 \sim 92$ microRNAs would alter proliferation. We transfected antagomiRs that targeted miR-17 92-encoded microRNAs into the human retinoblastoma cell lines and examined effects on cell proliferation. In Y79 and Weri-Rb1 retinoblastoma cell lines, antagomirs targeting $m i R-19 a / b$ didnot alter cell proliferation compared with scrambled control antagomir treatment (Fig. 5A). In contrast, antagomiRs targeting $m i R-17$ and $m i R-20$ together led to a strong reduction in proliferation (Fig. 5A). Inhibition of $m i R-17 / 20$ also led to up-regulation of p21Cip1, consistent with p21Cip1 being a direct reported target of miR-17/20 (Fig. 5B). We did not find alterations in the candidate miR-17 92 effectors p57Kip2 or p130 following antagomiR treatment in human retinoblastoma cell lines (data not shown). These data indicate that miR-17/20 inhibition suppresses proliferation in retinoblastoma cell lines, while miR-19 inhibition has little consequence. Moreover, our observations of p21Cip1 upregulation upon $m i R-17 \sim 92$ inhibition in human retinoblastoma cells and p21Cip1 suppression upon $m i R-17 \sim 92$ overexpression in murine retinas suggested that p21Cip1 may be a critical $m i R-17 \sim 92$ target in retinoblastoma.

\section{p21Cip1 inactivation increases proliferation in $\mathrm{Rb} / \mathrm{p} 107 \mathrm{DKO}$ retina}

Our data suggested that p21Cip1 up-regulation might compensate for $\mathrm{Rb} / \mathrm{p} 107$ deficiency in the murine retina to suppress proliferation. To test this notion in vivo, we performed compound mutant analyses, crossing a p21Cip1null allele into the $R b / p 107 D K O$ model. We compared the phenotype of $R b / p 107 / p 21 T K O$ mice with $R b / p 107 D K O$ littermate controls. Inactivation of p21Cip1 strongly increased proliferation in $R b / p 107 D K O$ retinas at $\mathrm{P} 22$, as assessed by BrdU analyses and $\mathrm{PH} 3$ immunostaining. (Fig. $5 \mathrm{C}, \mathrm{D})$. These data reveal an important physiological role for p21Cip1 up-regulation in restraining the effects of $R b$ family member deletion. Our data suggest a model in which the levels of $m i R-17 \sim 92$ dictate the response to $R b$ family deletion (Fig. 6). In cells with low levels of $m i R$ 17 92, compensatory up-regulation of p21Cip1, along with other CDKIs, limits proliferation following $R b$ deletion. High levels of $m i R-17 \sim 92$ partially suppresses this compensatory response and synergizes with $R B$ mutation to drive tumorigenesis.

\section{Discussion}

miR-17 92 is emerging as a critical oncogenic microRNA cluster in humans, found amplified in B-lymphomas, smallcell lung cancer, and other tumors (Mendell 2008). Our
A
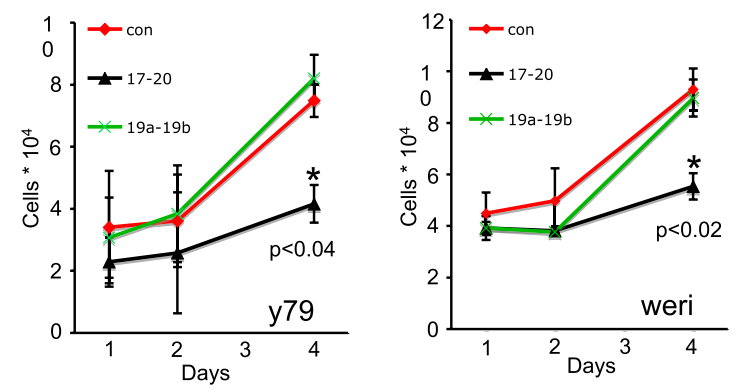

B

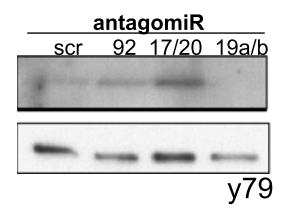

C

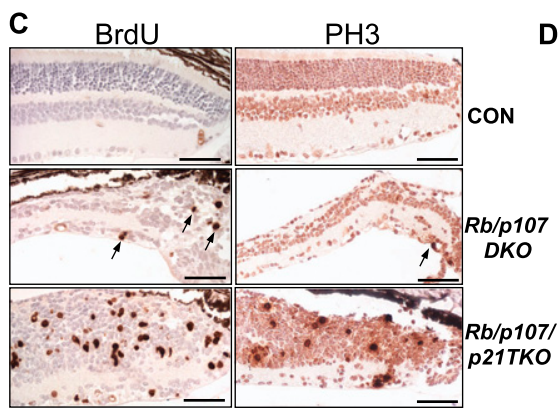

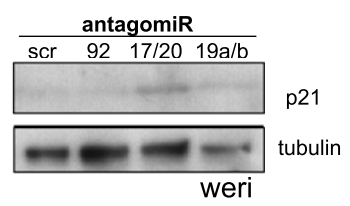

D

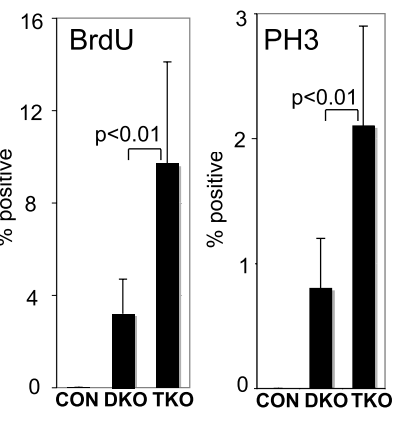

Figure 5. p21Cip1 is repressed by $m i R-17 / 20$ and inhibits proliferation in $R b / p 107 D K O$ retina. (A) Proliferation curves following transfection of $\mathrm{Y} 79$ and Weri-Rb1 cells with scrambled antagomir or anti-miR-19a/19b or anti-miR-17/20. Plotted are mean live cell counts from three independent experiments. (B) AntagomiR treatment of Y79 and WERI cells results in increased expression of p21Cip1 upon inhibition of miR-17/miR-20. (C) PH3 immunostaining and BrdU analyses show increased proliferation upon p21Cip1 deletion in P22 retinas lacking $\mathrm{Rb}$ and p107. Bar, $50 \mu \mathrm{m}$. Data are quantified in $D$. For BrdU and PH3 data, $n=5-8$ independent retinas per data point. Error bars indicate the standard deviation. $P$-value from Student's $t$-test is indicated. 

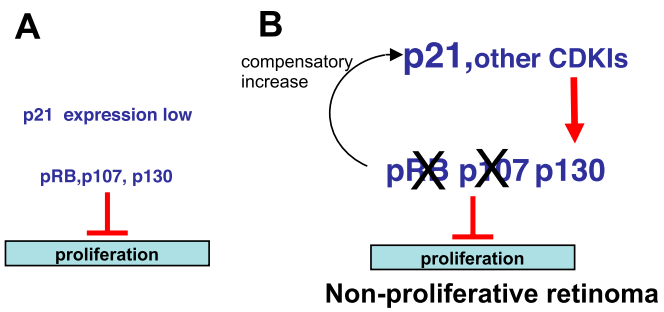

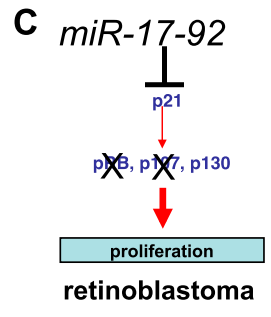

Figure 6. Model for synergism between $R b$ family and $m i R-17 \sim 92$ in tumorigenesis. $R b$ family member loss leads to compensatory p21Cip 1 up-regulation, which may be suppressed depending on the level of miR-17 92. Genomic miR-17 92 amplification in $R b / p 107 D K O$ mice leads to suppression of p21Cip1 and to bypass of cell cycle exit/arrest. High miR-17 92 expression in some cells (e.g., human retinoblastoma cells) may allow for evasion of this compensatory pathway even without genomic alterations. work now extends miR-17 92 oncogenic function to retinoblastoma. In myc-induced lymphoma, $m i R-17 \sim 92$ oncogenic effects were mediated by a miR-19-PTEN axis toward suppression of apoptosis ( $\mathrm{Mu}$ et al. 2009; Olive et al. 2009). In contrast, we found that PTEN was not reduced and apoptosis levels were not suppressed upon increased $m i R-17 \sim 92$ overexpression in a murine retinoblastoma model. Our data reveal that in retinoblastoma, miR-17 92 acts via proliferation control to promote tumorigenesis. These experiments implicate not $m i R-19$ but $\mathrm{miR}-17 / 20$ as conferring oncogenic activity in retinoblastoma. Moreover, these findings suggest that the levels of $m i R-17 \sim 92$ have a critical impact on the tumorigenic effects of $R B$ family member loss.

We found no detectable phenotypes upon $\operatorname{miR}-17 \sim 92$ overexpression alone in the retina. However, upon inactivation of $R b$ family members, $m i R-17 \sim 92$ overexpression leads to explosive growth of retinoblastoma. This reveals dramatic synergy between $m i R-17 \sim 92$ expression and $R b / p 107$ loss. The retinoblastoma that emerged aggressively invaded the optic nerve and metastasized to the brain. We noted that in the $R b / p 107 D K O$ retina, only a small proportion of $R b / p 107 D K O$ cells were still proliferating by $\mathrm{P} 22$, while in $R b / p 107 \mathrm{DKO}$ $R 26^{17 \sim 92 / 17 \sim 92}$ retinas, a proliferation block was evaded (Fig. 4B,D). Our molecular analyses revealed widespread up-regulation of numerous CDKIs in $R b / p 107$-deficient retinas, including p21Cip1 and p57Kip2 (Fig. 4; Supplemental Fig. 6). We also found that deletion of $R b$ alone in the retina, with p107 intact, leads to compensatory p21Cip1 up-regulation (D MacPherson, unpubl.). Compensatory up-regulation of CDKIs may bolster the activity of the RB family member p130 to inhibit proliferation (see model in Fig. 6). Indeed, we showed previously that p130 is a potent retinoblastoma suppressor in mice (MacPherson et al. 2004, 2007). Our molecular analyses of $\mathrm{P} 12$ retinas supports the idea that $m i R-17 \sim 92$ synergizes with $R b$ loss by suppressing a compensatory p21Cip1/CDK/ p130 axis that restrains the effects of $R b / p 107$ deletion (Fig. 6). We found that $\mathrm{p} 21 \mathrm{Cip} 1$, a validated target of $\mathrm{miR}$ 17 and $m i R-20$, was down-regulated upon $m i R-17 \sim 92$ overexpression in murine retinas (Fig. 4E). miR-17 92 amplification with consequent suppression of $\mathrm{p} 21 \mathrm{Cip} 1$ may override a proliferative block and drive the emergence of retinoblastoma. Evidence of the importance of compensatory p21Cip1 up-regulation in limiting the effects of $R b$ family deletion came in our findings that inactivation of $\mathrm{p} 21 \mathrm{Cip} 1$ in $R b / p 107 D K O$ retinas resulted in increased proliferation in vivo (Fig. 5C). p21Cip1 is not deleted in human or murine retinoblastomas. In human retinoblastoma, our data suggest that high $m i R-17 / 20$ levels repress p21Cip1 expression (Fig. 5). In murine retinoblastoma models, we hypothesize that there may be multiple mechanisms in addition to $m i R-17 \sim 92$ amplification to bypass compensatory up-regulation of p21Cip1 and other CDKIs following $R b / p 107$ deletion. It will be critical for future work to test whether other secondary alterations in mouse retinoblastoma models also converge on $\mathrm{p} 21 \mathrm{Cip} 1$ or act at other points in the pathway.

Human retinoblastomas exhibited high levels of $m i R$ 17 92 microRNAs relative to murine retinoblastoma (Fig. 1E,F). High miR-17 92 expression in human retinoblastoma may reflect the normal $m i R-17 \sim 92$ expression in the retinoblastoma cell of origin, and/or a response to $R B$ deletion in this cell type. Indeed, $m i R-17 \sim 92$ is an $E 2 F$ target gene (Sylvestre et al. 2007; Woods et al. 2007), and loss of $R B$ may lead to increased miR-17 92 through derepressed E2F activity. In some cell types, high levels of $m i R-17 \sim 92$, even without genomic amplification, may reduce the number of genetic "hits" required for tumorigenesis. Our results lead to a hypothesis that human retinoblastoma may be a fast-track cancer because high miR-17 92 expression in an $R B$-deleted retinoblast obviates the need for certain mutations. Mice are resistant to retinoblastoma upon $R b$ loss. Such resistance correlates with our observations that murine retinoblastomas exhibited far lower levels of miR-17 92 than human retinolastomas, except when the locus was the target of an amplification event (Fig. 1E,F). Differences in the expression of miR-17 92 microRNAs between differing cell types may strongly influence the number of hits required for tumorigenesis.

Our results emphasize the importance of context in microRNA oncogenic function. PTEN is an important target of miR-19 in some contexts, such as in $M y c$ induced lymphoma ( $\mathrm{Mu}$ et al. 2009; Olive et al. 2009). Moreover, $m i R-19$ appears to act via suppression of apoptosis (Mu et al. 2009; Olive et al. 2009; Mavrakis et al. 2010). However, we found no evidence of a miR-19/PTEN axis contributing to $m i R-17 \sim 92$ oncogenic function in retinoblastoma cells. In retinoblastoma, $\mathrm{miR}-17 \sim 92$ promoted tumorigenesis via effects on proliferation control. In retinoblastoma cell culture, $m i R-17 / 20$ inhibition led to strong suppression of proliferation and up-regulation of $\mathrm{p} 21 \mathrm{Cip} 1$. These data support the candidacy of $\mathrm{miR}$ $17 / 20$ as important oncogenic determinants of $\mathrm{miR}$ 17 92 in retinoblastoma. However, it will be critical for future work to assess the individual contribution of 
the differing miR-17 92-encoded microRNAs in retinoblastoma in vivo using mouse models. Also, the factors that dictate which miR-17 92 microRNAs and targets drive tumorigenesis across differing tissue types will be interesting to explore.

Our observations that miR-17 92 overcomes compensatory responses to $R b$ deletion lead to a prediction that high levels of miR-17 92 may synergize with $R b$ loss across other cancer types. Indeed, miR-17 92 overexpression or amplification is found in small-cell lung cancer (Hayashita et al. 2005), a highly aggressive and metastatic tumor type that, like retinoblastoma, undergoes very frequent $R B$ deletion. It will be important to determine whether miR-17 92 suppresses compensatory responses to $R B$ loss in diverse cell types, and whether $m i R-17 \sim 92$ is a critical $R B$ collaborator across diverse tumor types. Finally, our data indicate that miR-17 92 microRNAs are important proproliferative factors in $R B$-deleted tumor cells. As a synergistic oncogenic partner with $R B$ loss in cancer, miR-17 92 may represent a new therapeutic target for treating $R B$-deficient tumors.

\section{Materials and methods}

\section{Mice}

R26LSL miR-17 92-expressing mice (Xiao et al. 2008), miR17 92-floxed mice, and miR-106b 25-null mice (Ventura et al. 2008) were described previously. p21Cip1-deficient mice (Brugarolas et al. 1995), Pax6 $\alpha$ enhancer-Cre transgenics (Marquardt et al. 2001), and NesCre1 transgenics (Trumpp et al. 1999) have also been described. Paternal inheritance of NesCre 1 transgene were used to generate the mice used in the described experiments. We showed previously that paternal inheritance of NesCre 1 leads to essentially complete recombination of a lox-stop-lox LacZ reporter allele in early progenitors across the entire retina (Supplemental Fig. 1 of MacPherson et al. 2004). The $R b$ lox allele (Sage et al. 2003) and $p 107^{-/-}$mice (Lee et al. 1996) were described previously. Genotyping was performed according to published protocols. All animal protocols were approved by the Carnegie Institution Department of Embryology Animal Care and Use Committee.

\section{MicroRNA microarray and Northern blot analyses}

Total RNA was isolated from human and murine retinoblastomas or normal retina using Trizol reagent (Invitrogen). All studies using human samples were approved by the Johns Hopkins Homewood Institutional Review Board and the Massachusetts Eye and Ear Infirmary Human Studies Committee. For E13.5 and E18.5 murine retina collection, timed matings were performed with the day of plug detection considered P0. RNA was isolated from pools of embryonic wild-type retinas. MicroRNA expression was analyzed by a custom microarray platform, as described (Thomson et al. 2004). Briefly, $5 \mu \mathrm{g}$ of total RNA was labeled with $\mathrm{Cy} 3$ and hybridized to a custom oligonucleotide array. Intensity values were background-subtracted and floored to $2 \times$ background levels. Data were median center-normalized by array and hierarchically clustered. The heat map in Figure $1 \mathrm{~F}$ indicates high expression (yellow) and low expression (blue) relative to the median value. Small RNA Northern blots were performed by initially separating $0.5 \mu \mathrm{g}$ of total RNA onto a $15 \%$ polyacrylamide-urea gel. RNA was then transferred to Immobilon $\mathrm{N}^{+}$membrane (Millipore) and probed to 5' end-labeled oligonu- cleotide probes. RNA probes to $m i R-17$ and $m i R-20 a$ were obtained from Ambion. U6 oligonucleotide probe was used as a loading control. $5^{\prime}$ end labeling was performed using the mirVANA Probe kit (Ambion). TaqMan microRNA assays (Applied Biosystems) were performed using a DNA Engine Opticon (Bio-Rad) according to the manufacturer's instructions; normalization was to the housekeeping small RNA $U 6 b$.

\section{MicroRNA deep sequencing}

The Illumina small RNA sample prep kit (version 3) was used to generate libraries from $1 \mu \mathrm{g}$ of total RNA derived from primary retinoblastomas or normal human FW18 fetal retina. Human fetal retinas were obtained from Advanced Bioscience Resources. Samples were sequenced using an Illumina HiSeq sequencer. Linker sequences were trimmed and high-confidence reads were aligned to the human genome (University of California at Santa Cruz hg18 assembly) and compared with the microRNAs from miRBase using the miRanalyzer Web server tool to identify perfect matches (Hackenberg et al. 2009).

\section{Array-CGH/ROMA analyses}

ROMA analyses of mouse retinoblastomas were performed using $85 \mathrm{~K}$ arrays at the Cold Spring Harbor Genome Center as previously described (Lakshmi et al. 2006; MacPherson et al. 2007). For human array-CGH studies, DNA from human retinoblastomas and leukocyte controls (where available) were sent to Roche/Nimblegen Systems, Inc., for array-CGH service using custom-designed $12,000 \times 135,000$ arrays that tiled across the chromosome $13 \mathrm{miR}-17 \sim 92$ region at high density, with a median distance between probes of 60 base pairs (bp). Chromosome 5 probe coverage included $m i R-106 b \sim 25$ at a lower median spacing of $27 \mathrm{~kb}$ per probe. Data were normalized using NimbleScan, segmentation analysis was performed using Nimblegen SegMnt, and SignalMap software was used to visualize the data.

\section{Immunohistochemistry/immunofluorescence/histology}

For immunofluorescence, eyeballs were collected and the cornea was pierced with a needle while immersed in $4 \%$ paraformaldehyde/PBS. Following fixation, the eyes were transferred to $30 \%$ sucrose/PBS and then embedded in OCT and frozen on dry ice. Fourteen-micron sections were cut and transferred to Superfrost plus slides (VWR). Analysis was performed on sections taken at the level of the optic nerve head. Frozen sections were stained overnight at $4^{\circ} \mathrm{C}$ with the following antibodies: syntaxin (Sigma), calbindin (Millipore), calretinin (Chemicon), Sox2 (Santa Cruz Biotechnology), and Glutamine Synthetase (BD Bioscience). Sections were imaged using a laser-scanning confocal microscope (Leica SP5). For paraffin sections, samples were processed and BrdU analysis performed as described (MacPherson et al. 2003). Four-micron paraffin sections at the optic nerve level were chosen for analysis. PH3 immunostaining was performed using anti-phospho-Ser10-Histone H3 (Millipore) following antigen retrieval in boiling citrate buffer as described (MacPherson et al. 2003). Apoptosis was assessed using the TUNEL (In Situ Cell Death Detection kit, Roche). For study of brain metastasis, heads were fixed in Bouin's fixative for $2 \mathrm{wk}$, decalcified, and processed to paraffin, and $4-\mu \mathrm{m}$ sections were stained with hematoxylin and eosin.

\section{TEM}

The retinoblastoma or optic nerve was dissected and fixed in gluteraldehyde, post-fixed in osmium tetroxide, dehydrated, and 
processed for microscopy. Ultrathin sections were cut and visualized using a Phillips Tecnai 12 electron microscope.

\section{Real-time RT-PCR}

Real-time RT-PCR was performed using a DNA Engine Opticon (Bio-Rad). Total RNA was extracted with Trizol (Invitrogen). cDNA synthesis was performed using Quantiscript Reverse Transcriptase (Qiagen), and SYBR green assay was performed using Quantitect kit (Qiagen) according to the manufacturer's instructions. Primers were designed using the Primer3 program. At least three independent samples, each in triplicate, were used for all measurements. Normalization was to $\beta$-actin. Melting curve analyses were performed to confirm the specificity of the reaction. Primer sequences are available upon request.

\section{Western blotting}

Peripheral retina was dissected from P12 retinas and homogenized in lysis buffer containing $50 \mathrm{mM}$ Hepes (pH 7.5), $150 \mathrm{mM}$ $\mathrm{NaCl}, 1 \%$ NP-40, $5 \mathrm{mM}$ EDTA, $50 \mathrm{mM} \mathrm{NaF}, 1 \mathrm{mM}$ sodium orthovanadate, and Complete protease inhibitor cocktail (Roche). Antibodies to p130 (BD Biosciences), PTEN (Cell Signaling), Cyclin A (C-19, Santa Cruz Biotechnology), Cyclin D1 (BD Biosciences), p21Cip1 (C-19, Santa Cruz Biotechnology), p27Kip1 (C-19, Santa Cruz Biotechnology), p57Kip2 (H-91, Santa Cruz Biotechnology), p18Ink4c (M168, Santa Cruz Biochtechnology), $\beta$-Tubulin (9F3, Cell Signaling), Bim (Cell Signaling), Active caspase 3 (Cell Signaling), and Cleaved PARP (Cell Signaling) were used.

\section{AntagomiR studies}

For antagomiR studies, Y79 cells were transfected in Optimem (Invitrogen) with antagomirs at an overall concentration of $5 \mu \mathrm{M}$ using Lipofectamine RNAiMax (Invitrogen) following the manufacturer's instructions. Cells were plated at 20,000 cells per well. Following staining with trypan blue, live cells were counted at 1, 2, and $4 \mathrm{~d}$ post-transfection. Cell lysates were collected $4 \mathrm{~d}$ post-transfection for Western blot analysis. RNA oligonucleotides were synthesized by Dharmacon with phosphorothioate linkages $\left({ }^{*}\right)$, 2-O-methyl $(\mathrm{m})$, and the cholesterol modifications indicated. AntagomiR 17: $\mathrm{mC}\left({ }^{\star}\right) \mathrm{mU}\left({ }^{\star}\right) \mathrm{mAmC}$ mCmUmG mC mAmC mUmGmU mA mAmG mCmAmC $\mathrm{mU}\left(^{\star}\right) \mathrm{mU}\left({ }^{\star}\right) \mathrm{mU}\left({ }^{\star}\right) \mathrm{mG}\left({ }^{\star}\right)-C h o l ~ 3^{\prime}$; antagomiR 19a: $\mathrm{mT}\left(^{\star}|\mathrm{mC}|^{\star}\right)$ mAmGmUmUmUmUmGmCmAmUmAmGmAmUmUmUm $\mathrm{GmC}\left({ }^{\star} \mid \mathrm{mA}\left({ }^{*} \mid \mathrm{mC}\left({ }^{*} \mid \mathrm{mA}\left({ }^{*}\right)-\mathrm{Chol} 3^{\prime}\right.\right.\right.$; antagomiR19b: $\mathrm{mT}\left({ }^{*} \mid \mathrm{mC}\left(^{*}\right)\right.$ mAmGmUmUmUmUmGmCmAmUmGmGmAmUmUmUm

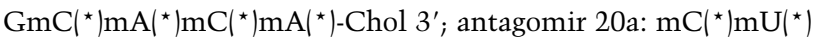
$m A m C m C m U m G m C m A m C m U m A m U m A m A m G m C m A m$ $\mathrm{CmT}\left(\left.{ }^{*}\left|\mathrm{mT}^{*}{ }^{*}\right| \mathrm{mT}\right|^{*}|\mathrm{~mA}|^{*}\right)-C h o l 3{ }^{\prime}$; antagomir 92a: $\mathrm{mC}\left({ }^{*}|\mathrm{~mA}|^{*}\right)$ mGmGmCmCmGmGmGmAmCmAmAmGmUmGmCmA ${ }^{*}$ ) $\left.\mathrm{mA}\right|^{*} \mid \mathrm{mU}\left({ }^{\star} \mid \mathrm{mA}\left({ }^{*}\right)-C h o l 3{ }^{\prime} ;\right.$ Control antagomiR-1: $\mathrm{mU}\left({ }^{*}|\mathrm{~mA}|^{*}\right)$ mCmAmUmAmCmUmUmCmUmUmUmAmCmAmUmU( $\left.{ }^{*}\right)$ $\mathrm{mC}\left({ }^{\star}|\mathrm{mC}|^{*}|\mathrm{~mA}|^{\star}\right)-\mathrm{Chol} \mathrm{3}$.

\section{Acknowledgments}

We are grateful to Klaus Rajewsky, Andrea Ventura, Tyler Jacks, Andreas Trumpp, and Peter Gruss for generously providing mouse strains used in the analysis. We thank Vuk Stambolic for providing Pten ${ }^{-/}$fibroblasts. We thank Mike Sepanski for TEM analyses, and Nick Ingolia for help with microRNA deepsequencing analyses. D. MacPherson designed experiments, executed experiments, and wrote the manuscript. K.C. and M.S. executed experiments. S.M. provided critical human reti- noblastoma samples. D. Mu oversaw ROMA analyses and analyzed data. J.M.T. performed microarray experiments, and S.H. oversaw microRNA microarray analyses and analyzed data. All authors critically discussed the results and the manuscript. D. MacPherson was supported by NIH grant 5R01CA148867 from the National Cancer Institute as well as grants from the Pearle Vision Foundation and the Knights Templar Eye Foundation. S.M. was supported by gifts to the Mukai Fund, Massachusetts Eye and Ear Infirmary.

\section{References}

Brugarolas J, Chandrasekaran C, Gordon JI, Beach D, Jacks T, Hannon GJ. 1995. Radiation-induced cell cycle arrest compromised by p21 deficiency. Nature 377: 552-557.

Burkhart DL, Sage J. 2008. Cellular mechanisms of tumour suppression by the retinoblastoma gene. Nat Rev Cancer 8: 671-682.

Chen D, Livne-bar I, Vanderluit JL, Slack RS, Agochiya M, Bremner R. 2004. Cell-specific effects of RB or RB/p107 loss on retinal development implicate an intrinsically death-resistant cell-of-origin in retinoblastoma. Cancer Cell 5: 539-551.

Clarke AR, Maandag ER, van Roon M, van der Lugt NM, van der Valk M, Hooper ML, Berns A, te Riele H. 1992. Requirement for a functional Rb-1 gene in murine development. Nature 359: 328-330.

Cloonan N, Brown MK, Steptoe AL, Wani S, Chan WL, Forrest AR, Kolle G, Gabrielli B, Grimmond SM. 2008. The miR-17-5p microRNA is a key regulator of the G1/S phase cell cycle transition. Genome Biol 9: R127. doi: 10.1186/gb-2008-9-8-r127.

Corson TW, Gallie BL. 2007. One hit, two hits, three hits, more? Genomic changes in the development of retinoblastoma. Genes Chromosomes Cancer 46: 617-634.

Dyer MA, Bremner R. 2005. The search for the retinoblastoma cell of origin. Nat Rev Cancer 5: 91-101.

Hackenberg M, Sturm M, Langenberger D, Falcon-Perez JM, Aransay AM. 2009. miRanalyzer: a microRNA detection and analysis tool for next-generation sequencing experiments. Nucleic Acids Res 37: W68-W76. doi: 10.1093/nar/gkp347.

Hayashita Y, Osada H, Tatematsu Y, Yamada H, Yanagisawa K, Tomida S, Yatabe Y, Kawahara K, Sekido Y, Takahashi T. 2005. A polycistronic microRNA cluster, miR-17-92, is overexpressed in human lung cancers and enhances cell proliferation. Cancer Res 65: 9628-9632.

He L, Thomson JM, Hemann MT, Hernando-Monge E, Mu D, Goodson S, Powers S, Cordon-Cardo C, Lowe SW, Hannon GJ, et al. 2005. A microRNA polycistron as a potential human oncogene. Nature 435: 828-833.

Ivanovska I, Ball AS, Diaz RL, Magnus JF, Kibukawa M, Schelter JM, Kobayashi SV, Lim L, Burchard J, Jackson AL, et al. 2008. MicroRNAs in the miR-106b family regulate $\mathrm{p} 21 / \mathrm{CDKN} 1 \mathrm{~A}$ and promote cell cycle progression. Mol Cell Biol 28: 21672174.

Jacks T, Fazeli A, Schmitt EM, Bronson RT, Goodell MA, Weinberg RA. 1992. Effects of an Rb mutation in the mouse. Nature 359: 295-300.

Johnson DA, Zhang J, Frase S, Wilson M, Rodriguez-Galindo C, Dyer MA. 2007. Neuronal differentiation and synaptogenesis in retinoblastoma. Cancer Res 67: 2701-2711.

Lakshmi B, Hall IM, Egan C, Alexander J, Leotta A, Healy J, Zender L, Spector MS, Xue W, Lowe SW, et al. 2006. Mouse genomic representational oligonucleotide microarray analysis: detection of copy number variations in normal and tumor specimens. Proc Natl Acad Sci 103: 11234-11239.

Lambertz I, Nittner D, Mestdagh P, Denecker G, Vandesompele J, Dyer MA, Marine JC. 2010. Monoallelic but not biallelic 
loss of Dicer1 promotes tumorigenesis in vivo. Cell Death Differ 17: 633-641.

Lee EY, Chang CY, Hu N, Wang YC, Lai CC, Herrup K, Lee WH, Bradley A. 1992. Mice deficient for $\mathrm{Rb}$ are nonviable and show defects in neurogenesis and haematopoiesis. Nature 359: 288-294.

Lee $\mathrm{MH}$, Williams BO, Mulligan G, Mukai S, Bronson RT, Dyson N, Harlow E, Jacks T. 1996. Targeted disruption of p107: functional overlap between p107 and Rb. Genes Dev 10: $1621-1632$.

Lu Y, Thomson JM, Wong HY, Hammond SM, Hogan BL. 2007. Transgenic over-expression of the microRNA miR-17-92 cluster promotes proliferation and inhibits differentiation of lung epithelial progenitor cells. Dev Biol 310: 442-453.

MacPherson D. 2008. Insights from mouse models into human retinoblastoma. Cell Div 3: 9. doi: 10.1186/1747-1028-3-9.

MacPherson D, Dyer MA. 2007. Retinoblastoma: from the twohit hypothesis to targeted chemotherapy. Cancer Res 67: 7547-7550.

MacPherson D, Sage J, Crowley D, Trumpp A, Bronson RT, Jacks T. 2003. Conditional mutation of $\mathrm{Rb}$ causes cell cycle defects without apoptosis in the central nervous system. Mol Cell Biol 23: 1044-1053.

MacPherson D, Sage J, Kim T, Ho D, McLaughlin ME, Jacks T. 2004. Cell type-specific effects of $\mathrm{Rb}$ deletion in the murine retina. Genes Dev 18: 1681-1694.

MacPherson D, Conkrite K, Tam M, Mukai S, Mu D, Jacks T. 2007. Murine bilateral retinoblastoma exhibiting rapid-onset, metastatic progression and $\mathrm{N}$-myc gene amplification. EMBO I 26: 784-794.

Marquardt T, Ashery-Padan R, Andrejewski N, Scardigli R, Guillemot F, Gruss P. 2001. Pax6 is required for the multipotent state of retinal progenitor cells. Cell 105: 43-55.

Martins RA, Zindy F, Donovan S, Zhang J, Pounds S, Wey A, Knoepfler PS, Eisenman RN, Roussel MF, Dyer MA. 2008. $\mathrm{N}$-myc coordinates retinal growth with eye size during mouse development. Genes Dev 22: 179-193.

Mavrakis KJ, Wolfe AL, Oricchio E, Palomero T, de Keersmaecker $\mathrm{K}$, McJunkin K, Zuber J, James T, Khan AA, Leslie CS, et al. 2010. Genome-wide RNA-mediated interference screen identifies miR-19 targets in Notch-induced T-cell acute lymphoblastic leukaemia. Nat Cell Biol 12: 372-379.

Mendell JT. 2008. miRiad roles for the miR-17-92 cluster in development and disease. Cell 133: 217-222.

Mu P, Han YC, Betel D, Yao E, Squatrito M, Ogrodowski P, de Stanchina E, D'Andrea A, Sander C, Ventura A. 2009. Genetic dissection of the miR-17 92 cluster of microRNAs in Myc-induced B-cell lymphomas. Genes Dev 23: 2806-2811.

Olive V, Bennett MJ, Walker JC, Ma C, Jiang I, Cordon-Cardo C, Li QJ, Lowe SW, Hannon GJ, He L. 2009. miR-19 is a key oncogenic component of mir-17-92. Genes Dev 23: 28392849.

Ota A, Tagawa H, Karnan S, Tsuzuki S, Karpas A, Kira S, Yoshida Y, Seto M. 2004. Identification and characterization of a novel gene, C13orf25, as a target for 13q31-q32 amplification in malignant lymphoma. Cancer Res 64: 3087-3095.

Poliseno L, Salmena L, Riccardi L, Fornari A, Song MS, Hobbs RM, Sportoletti P, Varmeh S, Egia A, Fedele G, et al. 2010. Identification of the miR-106b 25 microRNA cluster as a proto-oncogenic PTEN-targeting intron that cooperates with its host gene MCM7 in transformation. Sci Signal 3: ra29. doi: 10.1126/scisignal.2000594.

Robanus-Maandag E, Dekker M, van der Valk M, Carrozza ML, Jeanny JC, Dannenberg JH, Berns A, te Riele H. 1998. p107 is a suppressor of retinoblastoma development in pRb-deficient mice. Genes Dev 12: 1599-1609.
Sage J, Miller AL, Perez-Mancera PA, Wysocki JM, Jacks T. 2003. Acute mutation of retinoblastoma gene function is sufficient for cell cycle re-entry. Nature 424: 223-228.

Sengupta S, Nie J, Wagner RJ, Yang C, Stewart R, Thomson JA. 2009. MicroRNA $92 \mathrm{~b}$ controls the G1/S checkpoint gene p57 in human embryonic stem cells. Stem Cells 27: 1524-1528.

Sylvestre Y, De Guire V, Querido E, Mukhopadhyay UK, Bourdeau V, Major F, Ferbeyre G, Chartrand P. 2007. An E2F/miR-20a autoregulatory feedback loop. J Biol Chem 282: 2135-2143.

Thomson JM, Parker J, Perou CM, Hammond SM. 2004. A custom microarray platform for analysis of microRNA gene expression. Nat Methods 1: 47-53.

Trumpp A, Depew MJ, Rubenstein JL, Bishop JM, Martin GR. 1999. Cre-mediated gene inactivation demonstrates that FGF8 is required for cell survival and patterning of the first branchial arch. Genes Dev 13: 3136-3148.

Ventura A, Young AG, Winslow MM, Lintault L, Meissner A, Erkeland SJ, Newman J, Bronson RT, Crowley D, Stone JR, et al. 2008. Targeted deletion reveals essential and overlapping functions of the miR-17 through 92 family of miRNA clusters. Cell 132: 875-886.

Wang Q, Li YC, Wang J, Kong J, Qi Y, Quigg RJ, Li X. 2008. miR17-92 cluster accelerates adipocyte differentiation by negatively regulating tumor-suppressor Rb2/p130. Proc Natl Acad Sci 105: 2889-2894.

Weinberg RA. 1995. The retinoblastoma protein and cell cycle control. Cell 81: 323-330.

Woods K, Thomson JM, Hammond SM. 2007. Direct regulation of an oncogenic micro-RNA cluster by E2F transcription factors. J Biol Chem 282: 2130-2134.

Xiao C, Srinivasan L, Calado DP, Patterson HC, Zhang B, Wang J, Henderson JM, Kutok JL, Rajewsky K. 2008. Lymphoproliferative disease and autoimmunity in mice with increased miR17-92 expression in lymphocytes. Nat Immunol 9: 405-414.

Zhang J, Schweers B, Dyer MA. 2004. The first knockout mouse model of retinoblastoma. Cell Cycle 3: 952-959. 


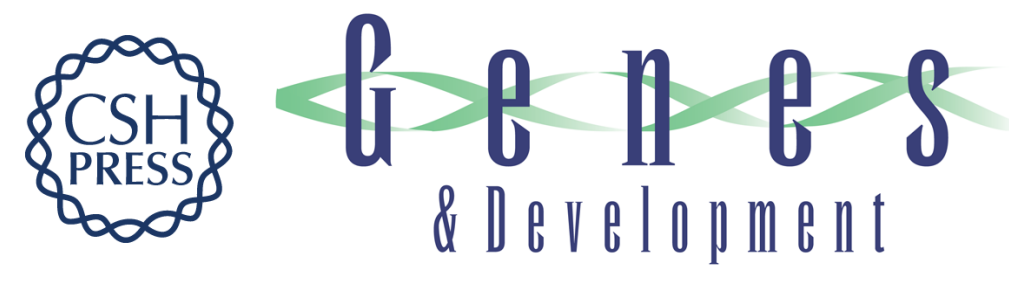

\section{miR-17 92 cooperates with $R B$ pathway mutations to promote retinoblastoma}

Karina Conkrite, Maggie Sundby, Shizuo Mukai, et al.

Genes Dev. 2011, 25: originally published online August 4, 2011

Access the most recent version at doi:10.1101/gad.17027411

\section{Supplemental http://genesdev.cshlp.org/content/suppl/2011/07/27/gad.17027411.DC1 \\ Material \\ Related Content \\ miR than meets the eye \\ Julien Sage and Andrea Ventura \\ Genes Dev. August, 2011 25: 1663-1667 \\ References This article cites 43 articles, 18 of which can be accessed free at: \\ http://genesdev.cshlp.org/content/25/16/1734.full.html\#ref-list-1 \\ Articles cited in: \\ http://genesdev.cshlp.org/content/25/16/1734.full.html\#related-urls \\ License \\ Email Alerting Receive free email alerts when new articles cite this article - sign up in the box at the top Service right corner of the article or click here.}

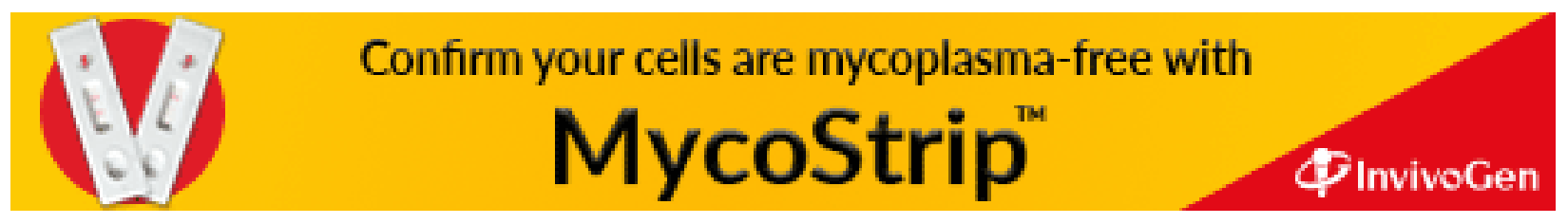

